\title{
EFFECT OF YOGASANAS ON MENSTRUAL CRAMPS IN YOUNG ADULT FEMALES WITH PRIMARY DYSMENORRHEA
}

\section{Shraddha Prabhu, Sanket Nagrale *, Ashok Shyam, Parag Sancheti.}

Sancheti Institute College Of Physiotherapy, Sancheti Healthcare Academy, 11/12 Thube Park, Shivajinagar, Pune -411005, Maharashtra, India.

\section{ABSTRACT}

Background: Dysmenorrhea- one of the most common gynecological complaints among young adult females. The effect of various yogasanas has proven to reduce the pain caused during menstruation as a result of hormonal changes. In spite of the various methods, most women usually prefer to take analgesics as a primary treatment and do not seek other forms of medical help. This study aims to underscore the importance of performing yogasanas and to highlight its importance as a non-pharmacological form of treatment.

Method: This study was an experimental study which included a total of 80 subjects. Age group was between 1822 years (mean age $20.3 \pm 2.1$ ). They were divided into 2 groups - experimental and control group .The experimental group were made to perform yogasanas while the control group was made to perform core exercises for 4 sessions in a week of which 2 were supervised sessions. Subjects were recruited using the Verbal Multidimensional Scoring System for Dysmenorrhea (VMSS) and they were assessed using Moo's Menstrual Distress Questionnaire and Perceived Stress Scale. Statistical analysis was done of the Pre and Post data.

Result: There was a significant difference within the groups (Experimental and Control) in regards to all the 3 outcome measures $(P<0.05)$. Between the groups, there was a significant difference $(P<0.05)$ in the VMSS and Moo's MDQ questionnaire while there was no significant change in the PSS score (P 0.641).

Conclusion: Both, yogasanas and core exercises can be used in reducing menstrual pain. These are cost effective and can be done as a home exercise to aid in menstrual well-being and to help improve one's quality of life.

KEY WORDS: Dysmenorrhea, Perceived Stress Scale, Moo's menstrual distress questionnaire, Verbal Multidimensional Scoring System, Yogasanas.

Address for correspondence: Nagrale Sanket (P.T), Sancheti Institute College Of Physiotherapy, Sancheti Healthcare Academy, 11/12 Thube Park, Shivajinagar, Pune-411005, Maharashtra, India.

E-Mail: nagralesanket@gmail.com

Access this Article online

Quick Response code

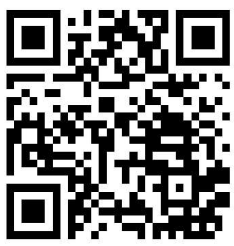

DOI: $10.16965 /$ ijpr.2019.140

Journal Information

International Journal of Physiotherapy and Research

ICV for 2016
86.93

ISSN (E) 2321-1822 | ISSN (P) 2321-8975

https://www.ijmhr.org/ijpr.html

DOI-Prefix: https://dx.doi.org/10.16965/ijpr

\section{Article Information}

Received: 04 Apr 2019

Peer Review: 12 Apr 2019

Revised: None
Accepted: 22 Apr 2019

Published (O): 20 Jun 2019

Published (P): 11 Aug 2019

\section{INTRODUCTION}

Dysmenorrhea, or painful menstruation is the most common gynecologic complaint among young adult females. It is mainly of two typesprimary and secondary. Dysmenorrhea in young adults is usually primary (functional) and is defined as cramping pain in the lower abdomen occurring just before or during menstruation. Secondary dysmenorrhea is dysmenorrhea which is associated with an existing pelvic pathology such as endometriosis which also includes menses pain $[1,2]$. Although it is a normal physiological process, many adolescents hardly have any knowledge regarding normal and abnormal menstruation [3] and do little to alleviate the symptoms.

The prevalence of primary dysmenorrhea (PD) that is mentioned in all the variety of studies conducted varies largely. Rates are as high as 
$67 \%$ to $90 \%$ for those aged between $17-24$ years[4,5]. In a cross sectional study conducted among 1000 healthy females aged 11-28 Indian girls showed a prevalence rate of $70.2 \%$ [6].

The cause of pain at the time of menses is believed to be due to the production of prostaglandins in the endometrium in an ovulatory cycle. It is one of the most important causes of absenteeism among adolescent girls as it affects their academic performance and also has a negative impact on quality of life [7]. The International Association for the Study of Pain has estimated that at each menstrual period, approximately $10 \%-15 \%$ of dysmenorrheic women are not able to work for 1 to 3 days [8].

Compared with normal women, women with primary dysmenorrhea tend to have an increased activity of the uterine muscles and increased uterine prostaglandins [9].

The inflammatory response mediated by these prostaglandins and leukotrienes, produces cramps and systemic symptoms such as nausea, vomiting, bloating. The prostaglandin F2a, cyclooxygenase (COX) which is a metabolite of arachidonic acid, causes potent vasoconstriction and myometrial contractions, further causing ischemia and pain [10].

There is little evidence of the relation between high stress levels and dysmenorrhea [11] although association has been found between high stress levels and irregular menstrual cycles. Stress enhances sympathetic activity which in turn increases menstrual pain by exacerbating uterine contractions [12].

In spite of the frequency and severity of dysmenorrhea, most women do not seek any medical treatment and usually prefer medications such as analgesics. However, analgesics are not an effective solution because of the risks for decreased effectiveness and increasing dependency $[13,14]$.

One study showed that a majority (98\%) of adolescents used non pharmacologic methods such as heat, rest, and distraction to treat dysmenorrhea, with perceived effectiveness of $40 \%$ or less [15]. Other forms of non pharmacological treatments such as aromatherapy, acupuncture, massage, topical heat, transcutaneous electrical nerve stimulation, behavioral interventions, dietary therapies, are increasingly attracting attention. ${ }^{16}$ Various other studies have shown different forms of exercise such as core strengthening and active stretching to be beneficial in coping with menstrual pain [17].

Yoga when performed as part of an exercise program helps in improving general health, improves flexibility, strengthens muscles and reduces pain [18]. Therefore, yoga can help mind and body adapt with stress which in turn makes one feel relaxed and calm [19]. Besides attaining physical fitness, yoga helps in reduction of the sympathetic nervous system tone and increases vagal activity, both of which could have favorable endocrine and immune consequences, including lowering inflammation $[20,21]$.

Various yoga postures have proven to be beneficial in alleviating symptoms related to menstrual pain. The aim of this study is to assess the effectiveness of selected yoga postures and core exercises on pain during menstruation and other symptoms observed during menstruation.

\section{MATERIALS AND METHODOLOGY}

To study the effect of yogasanas on menstrual cramps in young adult females, subjects were divided into experimental and control groups by convenient sampling. 80 college students between 18-25 years of age were selected from various colleges in Pune and assigned to experimental $(n=40)$ and control groups $(n=40)$. 2 subjects could not comply with the research protocol and hence were excluded from this study. Prior informed consent was taken from the subjects and the respective colleges.

Inclusion criteria: Age group 18-22 years, regular menstrual cycle, moderate to severe pain intensity on the VMSS scale, sexually inactive.

Exclusion criteria: No other medical or gynecological history, subjects not able to attend regularly Subjects were screened using the Verbal Multidimensional Scoring System for dysmenorrhea and were included if pain intensity was 2, 3 on the scale for both the groups.

They were explained about the study and given information, both verbally and in written format about how it would benefit them. Subjects were evaluated for one cycle. 


\begin{tabular}{|l|c|c|c|}
\hline \multicolumn{1}{|c|}{ Grade } & Working Ability & Systemic Symptoms & Analgesia \\
\hline $\begin{array}{l}\text { Grade 0: Menstruation is not painful and daily activity in } \\
\text { unaffected }\end{array}$ & Unaffected & None & Not Required \\
\hline $\begin{array}{l}\text { Grade 1: Menstruation is painful but seldom inhibits the } \\
\text { woman's normal activity. Analgesics are seldom } \\
\text { required. Mild pain }\end{array}$ & Rarely Affected & None & Rarely Required \\
\hline $\begin{array}{l}\text { Grade 2: Daily activity affected. Analgesics required and } \\
\text { give relief so that absence from work or school is } \\
\text { unusual. Moderate pain. }\end{array}$ & $\begin{array}{c}\text { Moderately } \\
\text { affected }\end{array}$ & Few & Pequired \\
\hline $\begin{array}{l}\text { Grade 3: Activity clearly affected. Poor effect of } \\
\text { analgesics. Vegetative symptoms, eg. Headache, } \\
\text { tiredness, nausea, vomiting and diarrhoea. Severe pain. }\end{array}$ & Clearly Inhibited \\
\hline
\end{tabular}

The questionnaires used were: Perceived stress scale, Menstrual Distress Questionnaire, Verbal Multidimensional Scoring System.

Prior to the beginning of the study, students were asked to fill out the questionnaires and post data was collected at the end of this research. The duration of this study was 6 weeks and the subjects had to perform the yogasanas (experimental group) and core exercises (control group) for 4 times a week, of which 2 were supervised sessions in their colleges. They were asked to carry their own mats. This intervention was not to be performed on the first 2 days of the menstrual cycle. Finally 78 subjects were included.

Semi structured questionnaire consisted of their menstrual cycle, pain scale on the VMSS, history of absteenism, use of analgesic during the cycle.

Group A: The experimental group $(n=40)$ was given the 2 questionnaires and were made to perform yogasanas which were the following poses: Bhujanagasana, Matsyasana, Vajrasana, Dhanurasana, Apanasana and Shavasana.

Asana were to be held for at least 10 seconds and performed for 5 repetitions.

Total duration was around 30 minutes with rest of 30 seconds between two asanas. Shavasana was to be performed at the end for 3-4 minutes.

Group B: Control group ( $\mathrm{N}=38$ ) was given the 2 questionnaires and were asked to do core strengthening exercises. They were asked to perform the following exercises:

1. Static core- Subjects had to perform this in supine position and were asked to contract their abdominals and hold it for 10 seconds.

2. Static back- Subjects were asked to place a towel below their back and were asked to press on the towel and hold for 10 seconds.
3. Bridging- Subjects were asked to flex their knees then contract their abdominals and then raise the pelvis and hold for 5 seconds.

4. Plank-Subjects were asked to lie in prone position and then raise the body by taking weight on the elbow and hold for 5 seconds.

5. Curl up- Subjects were asked to lie supine and flex both the knees, clasp both hands behind the head and move the body towards the knee and hold for 5 seconds.

All the above exercises were given in repetitions of 10 . Total duration was around 15- 20 minutes with a rest interval of 30 seconds.

A record was maintained by every individual for the outcome measures as pre and post data

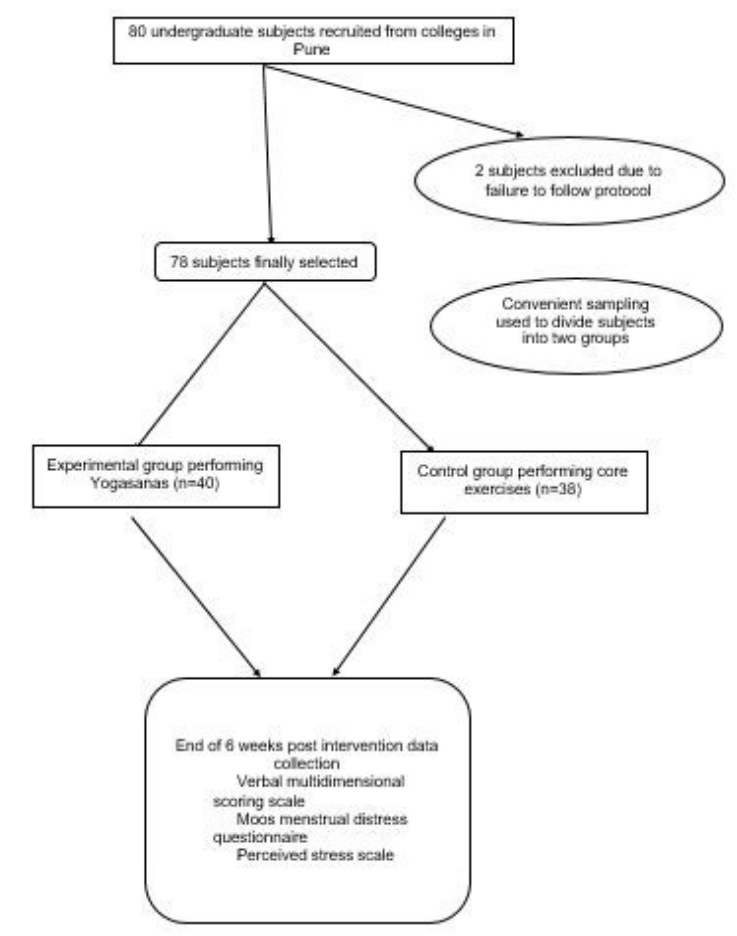

\section{RESULTS}

Statistical analysis was done using Wilcoxon signed rank test for within the group analysis for pre and post data and Mann Whitney was 
used between the experimental and control group. Data analysis was done using Microsoft excel and SPSS 16 version. Value of $(P<0.05)$ was considered significantly different.

Table 1: Results of Wilcoxon signed rank test (Experimental Group).

\begin{tabular}{|c|c|c|c|c|c|}
\hline \multirow{2}{*}{ Groups } & \multirow{2}{*}{$\mathbf{N}$} & \multirow{2}{*}{ Content } & \multicolumn{2}{|c|}{ Mean } & \multirow{2}{*}{ P value } \\
\cline { 3 - 6 } & & & Pre-mean \pm SD & Post mean \pm SD & \\
\hline \multirow{3}{*}{ Experimental } & \multirow{2}{*}{40} & PSS & $25.025 \pm 4.20$ & $21.05 \pm 4.44$ & 0 \\
\cline { 3 - 6 } & & MDQ & $105.775 \pm 13.68$ & $76.725 \pm 15.40$ & 0 \\
\cline { 3 - 6 } & & VMSS & $2.45 \pm 0.50$ & $0.875 \pm 0.72$ & 0 \\
\hline
\end{tabular}

$\mathrm{n}=$ total number of participants, $\mathrm{SD}=$ Standard deviation

Table 2: Results of Wilcoxon signed rank test (Control group).

\begin{tabular}{|l|c|c|c|c|c|}
\hline \multirow{2}{*}{ Groups } & \multirow{2}{*}{$\mathbf{N}$} & \multirow{2}{*}{ Content } & \multicolumn{2}{|c|}{ Mean } & P value \\
\cline { 4 - 6 } & & & Pre-mean \pm SD & Post mean \pm SD & \\
\hline \multirow{3}{*}{ Control } & \multirow{3}{*}{38} & PSS & $23.86 \pm 3.60$ & $21.18 \pm 2.98$ & 0 \\
\cline { 3 - 6 } & & MDQ & $117.02 \pm 10.45$ & $97.02 \pm 13.84$ & 0 \\
\cline { 3 - 6 } & & VMSS & $2.55 \pm 0.503$ & $1.55 \pm 0.68$ & 0 \\
\hline
\end{tabular}

Table 3: Results of Mann Whitney test (Between groups).

\begin{tabular}{|c|c|c|c|}
\hline & PSS & MDQ & VMSS \\
\hline P value & 0.641 & 0 & 0 \\
\hline
\end{tabular}

Graph 1: Comparison within the groups.

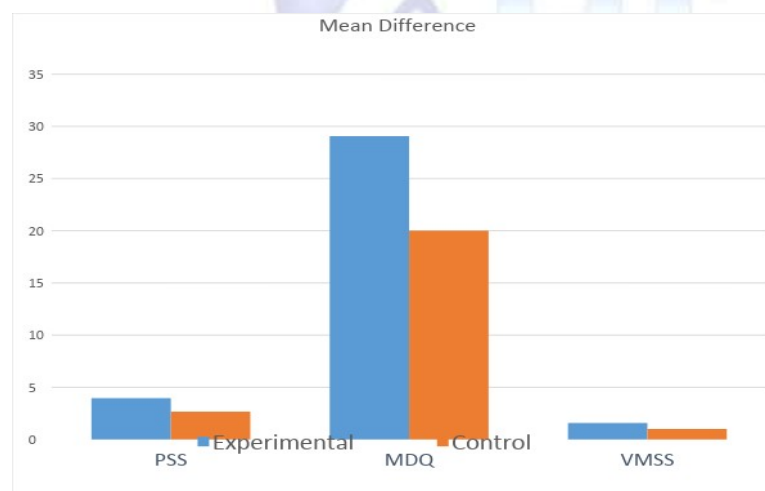

\section{DISCUSSION}

In this study the mean age of students was 20.3 \pm 2.1 . The students were asked not to perform the exercises on the first 2 days of their menstrual cycle. On statistical analysis a significant decrease was found in pain intensity, menstrual symptoms and stress in both yogasanas and the control group ( $p$ value $<0.05)$. The average menstrual cycle length in both the groups during in this study was 6 days. In the experimental group ( $n=40)$, majority of the subjects (52.5\%) experienced complete pain relief, $27.5 \%$ experienced mild discomfort on the first day of the cycle, $12.5 \%$ subjects experienced mild pain relief and $7.5 \%$ subjects made use of analgesics as cycle started as they had exams.
As shown in Table 1, there is a significant difference $(P<0.05)$ in all the outcome measures of the experimental group. This suggests that yogic exercises are helpful in reducing menstrual pain. This is consistent with the findings of Nam-Young Yang. The study showed that menstrual pain intensity $(p=0.001)$ and menstrual distress $(p<0.0001)$ measured using VAS and Moos MDQ scores decreased significantly in the experimental group compared to the control group who did not receive any intervention.

Yoga is known to play an important role in reducing stress and sympathetic activity, increasing parasympathetic activity, improving one's quality of life, and also by decreasing psychological symptom levels [22]. It also has beneficial effects on physical and mental health problems through downregulation of the hypothalamic- pituitary-adrenal axis and the sympathetic nervous system, which may also be useful for managing primary dysmenorrhea by reducing menstrual pain [23]. Yoga helps in increasing the flow of vital energy to the reproductive organs and establishes a balance among hormones regulating menstruation. Exercising affects the levels of steroid hormones in blood circulation of women in reproductive ages $[24,25]$. Any form of exercise is known to release endorphins which is produced by the brain that raises the pain threshold [26]. Postures help to stimulate the nervous system from with sensory input from all over the body. The asanas used in this study help in the following ways:

Bhujangasana: This asana is known to tone the female reproductive system- the uterus and the ovaries thereby alleviating menstrual pain and reducing stress. It also helps by stretching the abdominal muscles. Matsyasana: It helps in improvimg flexibility of the spine and also stimulates the abdomen increasing blood supply to the pelvic organs. Vajrasana: This asana helps in relaxation of pelvic floor muscles which reduces the stimuli passing through the spasmodic muscles leading to pain relief [27].

Dhanurasana: It stimulates the uterus and also increases the blood flow and relieves back pain during menstruation It also stretches the muscles of the posterior aspect of trunk, ankles, 
and groin.

Apanasana: Forward flexing to compress the abdomen helps in stimulating the enteric nervous system. Shavasana includes lying down and relaxing. When one is relaxed the sympathetic effect on various organs is diminished, the muscle tone in smooth muscles is reduced which allows vessels to dilate, increasing the blood supply [28].

Table 2 shows that there is a significant difference $(P<0.05)$ in all the outcome measures of the Control group. During menstruation weak core musculature creates an inability for the body to handle forces required for normal movement and function thus causing improper biomechanical function of structures adjacent to the lumbar spine. If the lumbar spine is weak or not able to handle functional stress then it can result in pain throughout the abdomen, low back and thighs. These also happen to be the area affected by the females during menstruation. As shown in table 2 the mean pain intensity measured by VMSS scale in the control group shows pain intensity to be reduced from $2.55 \pm 0.503$ to $1.55 \pm 0.68$ (mean \pm SD). This suggests the need of core strengthening to reduce menstrual symptoms. Isometric exercises is known to cause contraction of a particular group of muscle which increases blood flow to that particular area. This finding is consistent with that reported by Sandeep Kaur. Pain reduction was found to be from 9.09 to 4 in 4 weeks to 0.97 in 8 weeks measured by using the Numerical Pain Rating Scale.

Another study showed the use of Gym Ball exercise in comparison to yogasanas for reducing PD. Gym ball exercises help in core strengthening and improving stability and were more significant in reducing pain compared to yogasanas which suggests that core strengthening exercises can be more beneficial [29] as core strengthening allows the small intrinsic musculature surrounding the lumbar spine to be conditioned for greater performance [30]. Similarly plank exercises helps in targeting the deeper muscles called the transversus abdominis and also the muscles of the spine [31] although literature points more towards yogasanas suggesting the need for further study in this aspect.
Table 3 shows a significant difference was observed between experimental and control groups in the Moos Menstrual Distress Questionnaires and VMSS using Mann-Whitney test. The results are similar to other studies done in the past $[17,18,21,22.28]$. There was no significant change observed in the PSS score ( $P$ value 0.641 ) between both the groups as stress can be influenced by various factors such as socioeconomic status. The relation between stress and dysmenorrhea may differ among groups of women as suggested by Clarvit [32]. As dysmenorrhea is not a disease in itself, a holistic approach can be used to tackle this problem.

\section{CONCLUSION}

The present result suggests that yogasanas and core strengthening both can be safely used for reducing symptoms related to primary dysmenorrhea.

It is cost effective and therefore it can be used as a home based treatment and can also be implemented among college students in order to augment their menstrual well-being and also their over-all well-being as it will also aid in improving physical fitness.

Regular exercises is recommended as it will help reduce absenteeism from work and improve quality of life. It will also help individuals to participate in various activities during menstruation.

Further study can be done with a larger sample size so as to provide better qualitative analysis, different population etc.

\section{ACKNOWLEDGEMENTS}

I would like to thank Dr. Dhara Kapoor (Former Research Co-ordinator) and Dr. Rachana Dabadgav (Research Co-ordinators at Sancheti Institute College of Physiotherapy) for their valuable guidance. I extend my gratitude to the college authorities for allowing me to conduct my research in their premises. I would like to thank our management and ethical committee for permitting me to undertake this study. Lastly, I extend my warm gratitude to all the people who have participated in this research.

\section{Conflicts of interest: None}




\section{REFERENCES}

[1]. Harel Z. Dysmenorrhea in adolescents and young adults: etiology and management. Journal of pediatric and adolescent gynecology. 2006 Dec 1;19(6):363-71.

[2]. Coco AS. Primary dysmenorrhea. American family physician. 1999 Aug;60(2):489-96.

[3]. Sharma M, Gupta S. Menstrual pattern and abnormalities in the high school girls of Dharan: a cross sectional study in two boarding schools. Nepal Med Coll J. 2003 Jun; 5 (1): 34-36.

[4]. Harlow SD, Ephross SA. Epidemiology of menstruation and its relevance to women's health, Epidemiol Rev , 1995, 17(2):265-286.

[5]. Kennedy S. Primary dysmenorrhea, Lancet, 1997 Apr 19;349(9059):1116.

[6]. Omidvar S, Bakouei F, Amiri FN, Begum K. Primary dysmenorrhea and menstrual symptoms in Indian female students: prevalence, impact and management. Global journal of health science. 2016;8(8):135.

[7]. De Sanctis V, Soliman AT, Elsedfy $H$, Soliman NA, Elalaily $\mathrm{R}$, el Kholy $\mathrm{M}$. Dysmenorrhea in adolescents and young adults: a review in different countries. Acta Biomed. 2016;87(1).

[8]. Habibi N, Huang M, Gan W, Zulida R, Safavi SM. Dysmenorrhea and factors associated with its intensity among undergraduate students: a cross-sectional study. Pain Manag Nurs. 2015;16(6):855-861.

[9]. Rosenwaks Z, Seegar-Jones G. Menstrual pain: its origin and pathogenesis. The Journal of reproductive medicine. 1980 Oct;25(4):207-12.

[10]. Alvin PE, Litt IF: Current status of etiology and management of dysmenorrhea in adolescents. Pediatrics 1982; 70: 516.

[11]. Karki Prabin Kumar, Rai Chandra Kala, Kharel Sushil, Khakurel Gita, Dysmenorrhea and its association with stress among female students of Kathmandu Medical College, Indian Journal of Basic and Applied Medical Research; June 2017; 6(3):554-558.

[12]. Nagma S, Kapoor G, Bharti R, Batra A, Batra A, Aggarwal $A$, et al. To evaluate the effect of perceived stress on menstrual function. Journal of Clinical and Diagnostic Research. 2015 March;9(3):QC01QC03.

[13]. Osayande A, Mehulic S. Diagnosis and initial management of dysmenorrhea. Am Fam Physician 2014;89:341- 346.

[14]. Perry M. Treatment portions for dysmenorrhea. Nurs Pract 2012;23:195-198.

[15]. Campbell MA, McGrath PJ: Non-pharmacologic strategies used by adolescents for the management of menstrual discomfort. Clin J Pain 1999; 15:313.

[16]. Han SH, Hur MH, Buckle J, Choi JY, Lee MS. Effect of aromatherapy on symptoms of dysmenorrhea in college student: a randomized placebo-controlled clinical trial. The Journal of Alternative and Complementary Medicine, 2006;12:535-541.

[17].Sandeep Kaur, Prabhnoor kaur, Sarvanan Shanmugam, Manpreet Kaur .To compare the effect of stretching and core strengthening exercises on Primary Dysmenorrhea in Young females.
IOSR Journal of Dental and Medical Sciences (IOSRJDMS), 2014; 13(6):22-32.

[18]. Rakhshaee Z. Effect of three yoga poses (cobra, cat and fish poses) in women with primary dysmenorrhea: a randomized clinical trial. Journal of Pediatric and Adolescent Gynecology 2011;24: 192-196.

[19]. Carlson KJ, Eisenstat SA, Ziporyn TD: The Harvard Guide to Women's Health. Cambridge Harvard University Press, 1996.

[20]. Kiecolt-Glaser, J.K., Christian, L., Preston, H., Houts, C.R., Malarkey, W.B., Emery, C.F., Glaser, R., Stress, inflammation, and yoga practice. Psychosom. Med. 2010;72 (2):113-121.

[21]. Usha Nag, M.D, [Obg], Pg Dip, M.Sc [Yoga], Madhavi Kodali, M.D.,D.P.M. Effect of Yoga on Primary Dysmenorrhea and Stress in Medical Students. IOSR Journal of Dental and Medical Sciences. 2013 JanFeb; 4(1): 69-73.

[22]. Yang NY, Kim SD. Effects of a yoga program on menstrual cramps and menstrual distress in undergraduate students with primary dysmenorrhea: a single-blind, randomized controlled trial. The Journal of Alternative and Complementary Medicine. 2016 Sep 1; 22(9):732-8.

[23]. Kanojia S, Sharma VK, Gandhi A, et al. Effect of yoga on autonomic functions and psychological status during both phases of menstrual cycle in young healthy females. Journal of Clinical and Diagnostic Research. 2013;7:2133-2139.

[24]. Warren MP, Perlroth NE. Hormones and sport: the effects of intense exercise on the female reproductive system. Journal of Endocrinology. 2001;170:311.

[25]. Jahromi M, Gaeini A, Rahimi Z. Influence of a physical fitness course on menstrual cycle characteristics. Gynecological Endocrinology. 2008;24:659-62.

[26]. Abbaspour Z, Rostami M, Najjar Sh. The effect of exercise on primary dysmenorrhea. J Res Health Sci. 2006;6:26-31.

[27]. S Dutta Ray, psychosomatic adaptation and yoga, yogic exercises physiologic and psychic process, chapter no.4, first edition, 1998:33-35.

[28]. Gauri S. Kulkarni, Nilima Bedekar, An Experimental Study of Selected Yoga Poses on Young Adult Female Population Reporting Primary Dysmenorrhoea. VIMSHSJ,(2014),1(3)Light Natasha, Palmer Nikki, Utrup Chris, the effects of core strengthening on Dysmenorrhea, 2006 Oct

[29]. Veena K, Padmanabhan K, Sudhakar S, Aravind S, Praveen Kumar C R, Monika S. Efficacy of Yoga Asana and Gym Ball Exercises in the management of primary dysmenorrhea: A single-blind, two group, pretest-posttest, randomized controlled trial. CHRISMED Journal of Health and Research. 2018;5:118-22.

[30]. Izzo A,Labriola D _Dysmenorrhoea and sports activities in adolescents.Clinical and Experimental Obstetrics and Gynecology. 1991;18(2):109-16.

[31].Green, Yolande. Weight-bearing Workouts for Women: exercises for Sculpting, Strengthening and toning. Berkely,CA:Ulysses, 2004.

[32]. Clarvit SR. Stress and menstrual dysfunction in medical students. Psychosomatics 1988;29:404-9. 